\title{
Magnetic resonance imaging in the diagnosis of spinal hydatid cyst disease. Case report
}

\author{
A Fahir Özer MD, ${ }^{1} \mathrm{M}$ Memet Özek MD, ${ }^{2} \mathrm{M}$ Necmettin Pamir MD,${ }^{3} \mathrm{C}$ Erzen $\mathrm{MD}^{4}$ \\ ${ }^{1}$ Associate Professor of Neurosurgery, ${ }^{2}$ Assistant Professor of Neurosurgery, ${ }^{3}$ Professor of \\ Neurosurgery, Department of Neurosurgery; ${ }^{4}$ Professor of Radiology, Department of \\ Radiology, Marmara University Faculty of Medicine, Istanbul, Turkey.
}

\begin{abstract}
A very rare case of multiple spinal hydatid disease causing paraplegia is presented. The neuroradiological evaluation included an MRI study. The surgical approach and the medical treatment of the disease is discussed, with a review of the literature.
\end{abstract}

Keywords: spinal hydatid cysts; MRI investigation.

\section{Introduction}

Hydatid cyst infestation is observed in the life cycle of the Echinococcus parasite which can encyst in a number of organs, resulting in many different clinical syndromes. Bone involvement occurs in $1 \%$ of cases, with the vertebral column being involved in $50 \%$ of those with bone infestation.

In this presentation of a patient with spinal hydatid cysts there were multiple localisations with compression on the spinal cord and extension into the thoracic cavity.

\section{Case report}

The patient is a 28 year old male who was admitted to hospital with paraplegia of sudden onset. He had been operated on in another neurosurgical center because of hydatid cyst disease, causing spinal cord compression at the T1-T3 level. He was admitted to our hospital because of motor loss in both lower extremities; this had resolved after the first operation but recurred in about 3 months. MRI investigation revealed the presence of hydatid cyst disease affecting the T1-T3 segments, where the previous operation had been carried out. It was found that the body of $\mathrm{T} 8$, the pedicles and posterior elements had been eroded by the infestation. Also, multiple cysts were identified involving the soft tissues of the back of the patient (Fig 1). Spinal cord compression was present. It was clearly demonstrated by the $\mathrm{T} 2$ weighted sections of the MRI investigation that multiple cysts, adjacent to each other, had been located in the $\mathrm{T} 1-\mathrm{T} 3$ region (Fig 2). Addition-

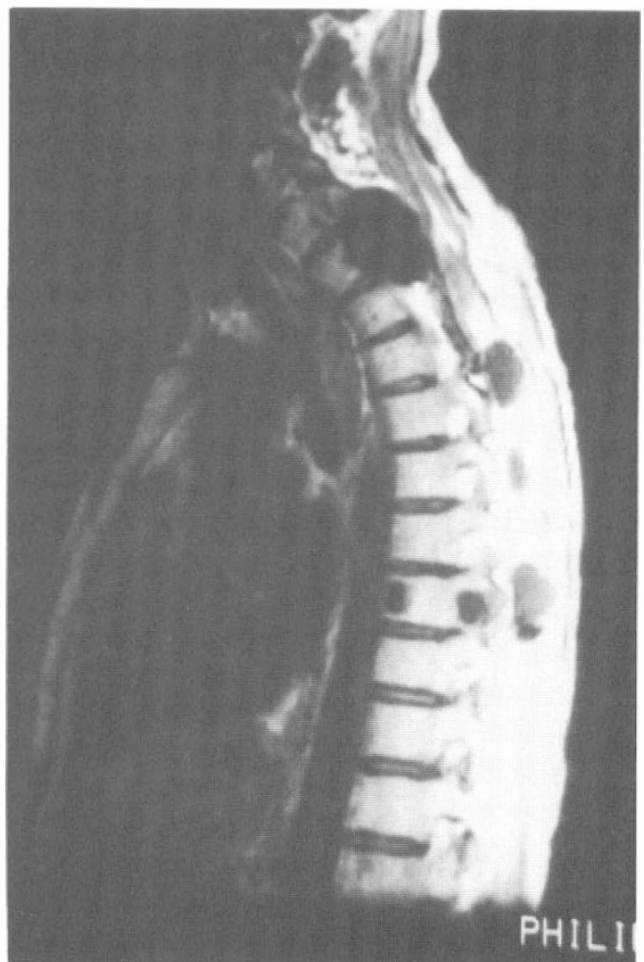

Figure 1 Preoperative MRI. Multiple hydatid cysts involving vertebrae and the soft tissues.

ally, in the vertical sections of that region, it was detected that the parasites had been encysted in the retropleural cavity (Fig 3 ).

The patient required emergency surgery, reoperating through the previous incisions, and cysts causing compression of the spinal cord epidurally and penetrating into the thoracic 


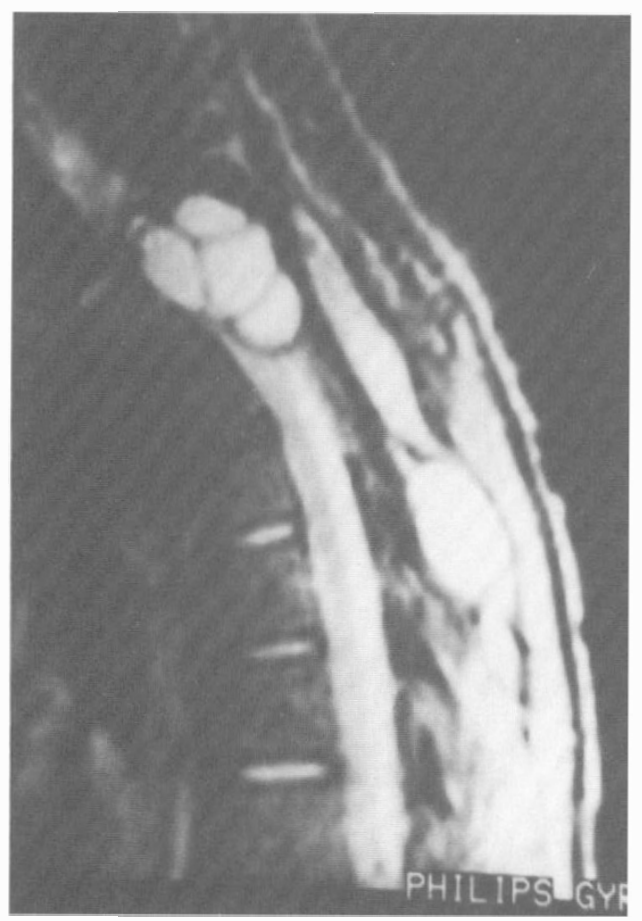

Figure 2 Preoperative MRI. T2 weighted MRI sections demonstrating multiple hydatid cysts.

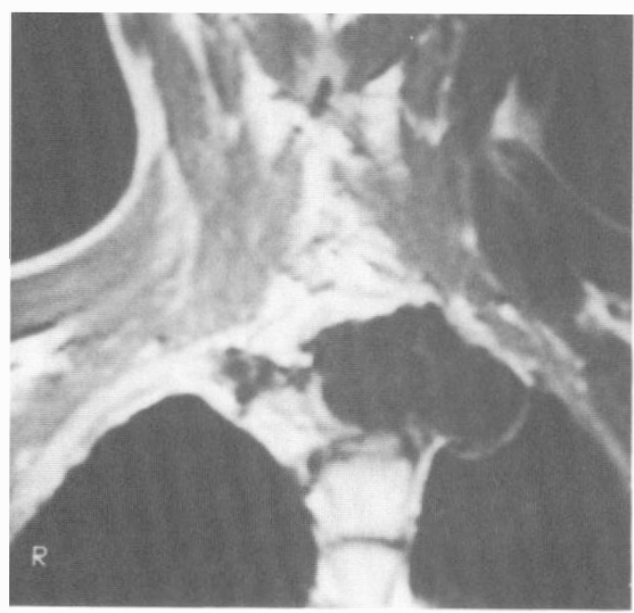

Figure 3 Preoperative MRI study demonstrating involvement of the thoracic cavity. cavity were excised. The surgical area was irrigated with hypertonic $\mathrm{NaCl}$ solution. The patient was discharged on the seventh postoperative day having been placed on albendazole. At the last follow up examination of the patient, 6 months after the second operation, it was noted that all of the neurological signs had disappeared. A control MRI investigation carried out then showed that the extradural compression had been relieved.

\section{Discussion}

There is a close relationship between the location of hydatid cysts and the severity and time of the onset of clinical symptoms. Intramedullary, intradural-extramedullary, or solitary extradural localisations of hydatid cysts are possible but are extremely rare. ${ }^{1-3}$ Usually, when neurological signs arise from these cysts involving the vertebrae there is extradural compression; or if the cysts arise in the paravertebral area there can be erosion of vertebrae, causing extradural spinal cord compression. ${ }^{4-8}$ In our patient, hydatid cysts developed in the area of the previous operation, and gave rise to extradural spinal cord compression, besides extending into the thoracic cavity after eroding the lateral part of the ribs and vertebrae. In the diagnosis computerised tomography has a special role to determine bone destruction. MRI investigaton, especially T2 sections, clearly reveals the hydatid cysts, which can be shown individually. Therefore CT and MRI techniques provide different but complimentary evidence for the diagnosis of hydatid cysts. ${ }^{4.5 .7-9}$

Concerning management, surgical decompression in association with albendazole is recommended. Preoperative irrigation of the surgical area with hypertonic or $\mathrm{AgNO}_{3}$ solutions is especially important. The prognosis with this therapy is promising but on the other hand, we feel that recurrence is inevitable when vertebrae are affected by the microvesicular type of hydatid cysts. ${ }^{4.5 .7 .10}$

\section{References}

1 Medyek L, Zenini S, Hamnoon S, Hartani M (1991) Intradural hydatiosis of the thoracic spine: A proposya case. Ann Radiol (Paris) 34(4): 251-255.

2 Akhan O, Dinler A, Saatçi I, Gülekon N, Besim A (1991) Spinal intradural hydatid cysts in a child: $B r J$ Radiol 64(761): 464-466. 
3 İplikçioğlu AC, Kökeş F, Bayar A, Doğanay S. Buharali S (1991) Spinal invasion of pulmonary hydatiosis; computed tomographic demonstration. Neurosurgery 29(3): 467-468.

4 Pamir MN, Akalin N. Özgen T, Erbengi A (1984) Spinal hydatid cyst. Surg Neurol 21: 53-57.

5 Charles RW, Govender S, Naido KS (1988) Echinoccal infection of the spine with neural involvement. Spine 13(1): 47-49.

6 Payport M, Wisoff HS, Zalman H (1964) Vertebral echinococcosis. J Neurosurg 21: 647-660.

7 Wan MA, Taheri SA, Babu ML, Ahangar GA. Wan H (1989) Primary extradural hydatid cyst. Neurosurgery 24(4): 631-632.

8 Kars HZ. Hekimoğlu B, Cepoğlu C (1990) Spinal epidural hydatid cyst. Radiological and ultrasonographical work up of a case. Eur J Radiol 19(3): 212-214.

9 Pav A, Simovetti G, Tortari-Donadi P, Turtus S, Viale GL (1987) Computed tomography and magnetic resonance imaging in spinal hydatiosis. Surg Neurol 27(4): 365-369.

10 Richards KS, Morris DL (1990) Effect of albendazole on human hydatid cysts on ultrastructural studies. HPB Surg 2(2): 105-112. 